\title{
Seismic input characterization for some sites in Italy
}

\author{
D. Rinaldis \& P. Clemente \\ ENEA, Rome, Italy
}

\begin{abstract}
The seismic input characterization is the first task in the analysis of the seismic behaviour of a structure. The definition of the seismogenetic sources, earthquake catalogue and site characteristics are preliminary to the study. The seismic input may be represented by means of a response spectrum or time-histories. There are many methodologies to produce response spectra and/or input time histories for a given site. The approach may be probabilistic, strictly deterministic or a mixture of both. A strictly deterministic approach is based on the identification of the maximum credible earthquake within an accepted return period. This can be achieved by taking into account both the seismicity historically observed at the site and the features of the seismic sources able to affect the site. The probabilistic hazard assessment is based on Cornell's methodology; it requires the definition of homogeneous seismic sources, their characterization in terms of maximum expected magnitude and Gutenberg-Richter relation (recurrence of events in different magnitude classes) and the choice of an attenuation law for seismic energy, according to the selected ground motion parameter. The methodology proposed by ENEA perform all tasks of the deterministic approach but requires also the comparison between the Fourier amplitudes of the selected time histories with the Uniform Hazard Spectrum (UHS) recovered from the probabilistic approach by means of a statistical index indicating the best fitting. Two case studies are shown.

Keywords: seismic input, seismic hazard, deterministic approach, probabilistic approach, risk analysis.
\end{abstract}




\section{Introduction}

Risk analysis is systematic use of available information to determine how often specified events may occur and the magnitude of their consequences. Risks are typically defined as negative events, such as losing money on a venture or a storm creating large insurance claims. Risk analysis can be performed qualitatively or quantitatively. Qualitative risk analysis generally involves assessing a situation by instinct or "good feel" and is characterized by statements, such as "That seems too risky" or "We'll probably get a good return on this". Quantitative risk analysis attempts to assign numeric values to risks, either by using empirical data or by quantifying qualitative assessments and is based on quantitative hazard evaluation.

As an example, in space exploration, probabilistic strategic analysis is used to simulate possible scenario outcomes, based upon the likelihood of occurrence of certain events and a set of pre-determined contingency rules. The results of the probabilistic analysis are compared to the nominal results from the deterministic analysis to evaluate the robustness of the scenario to adverse events and to test and optimize contingency planning [1]. To understand when the use of probabilistic method is advantageous compared to the deterministic one in the determination of seismic hazard, it is necessary checking the specific situation. Probabilistic methods can be viewed as inclusive of all deterministic events with a finite probability of occurrence. In this context, proper deterministic methods that focus on a single earthquake ensure that the analyzed event is realistic, i.e., that it has a finite probability of occurrence. According to some authors [2], this points to the complementary nature of deterministic and probabilistic analyses: deterministic events can be checked with a probabilistic analysis to ensure that the event is realistic (and reasonably probable), and probabilistic analyses can be checked with deterministic events to see that rational, realistic hypotheses of concern have been included in the analyses.

Whatever the purpose of the study, the result will be used to make a decision: the selection of a methodology for the design of a structure or its seismic, financial planning for the losses associated with a seismic event (in Italy there are no laws, which provide levels of insurance or reinsurance or self-insurance, to face catastrophic events and the Civil Protection provides for these needs), any investments for redundant industrial systems, planning for emergency response and post-earthquake recovery, and planning for long term recovery. Such decisions are best served with both deterministic and probabilistic perspectives, and the best analyses are conducted knowing the decisions to be made. The more you need to make a decision that needs a quantitative definition, the more the probabilistic analysis is appropriate.

In this paper, after a general view on the probabilistic and deterministic approaches to define the seismic input, the methodology proposed by ENEA is presented and two case studies are illustrated. 


\section{Probabilistic and deterministic approaches}

The seismic input characterization is the first task in the analysis of the seismic behaviour of a structure. The definition of the seismogenetic sources, earthquake catalogue and site characteristics (surface geology, geotechnical parameters, morphology etc.) are preliminary to the study.

A strictly deterministic seismic-hazard analysis (DSHA) is based on the identification of the maximum credible earthquake within an accepted return period. This can be achieved by taking into account both the seismicity historically observed at the site and the features of the seismic sources able to affect the site. The design earthquake is characterized in terms of magnitude, focal mechanism and distance from the site. Maximum local intensities and site conditions in terms of shear-waves profiles or at least according to a soil classification must also be considered. The obtained earthquake and site parameters are then used to sort out accelerograms recorded in similar conditions.

The probabilistic hazard assessment (PSHA) is based on the Cornell's methodology [3]. It requires the definition of homogeneous seismic sources (each point inside the source is assumed to have the same probability of being epicenter of a future earthquake), their characterization in terms of maximum expected magnitude and Gutenberg-Richter relation (recurrence of events in different magnitude classes) and the choice of an attenuation law for seismic energy, according to the selected ground motion parameter. The feature of PSHA about which there is perhaps the greatest degree of misunderstanding is the treatment of the random variability in ground motion prediction equations, which exerts a very pronounced influence on the calculated hazard [4].

In the literature, one can find an extensive and often polemic debate about the reliability of DSHA and PSHA. According to some authors [5-7], these discussions generally do little to illuminate matters and are also rather futile; since the equations used to predict the ground motion are probabilistic, it is actually impossible to perform a fully deterministic evaluation of the seismic hazard (setting the residual $=0$ corresponds to a $50 \%$ chance of exceeding the design ground motion if the selected scenario earthquake occurs). The fundamental difference between DSHA and PSHA is that the former considers just one (or sometimes a few) magnitude (M), distance (D) and residual (r) scenario, whereas PSHA calculates the rate at which different levels of ground motion are exceeded at the site by considering the effects of all possible combinations of M, D, and $\mathrm{r}$. Using DSHA for critical facilities, it is common to set $r=1$ [8] and consider this to be a worst-case scenario. In this way the $16 \%$ probability that design ground motions could be exceeded for the chosen M-D scenario is ignored.

Wang [9] observed that PSHA has no valid physic and mathematic basis and does not use a valid earthquake source model. He proposed the seismic hazard analysis (SHA), which uses the statistical relationships of earthquake occurrence frequency, the Gutenberg-Richter relationship and ground motion prediction earthquake (GMPE). For the considered case study, he considered a single 
characteristic earthquake for the seismic source. This example also demonstrates that hazard calculation in SHA is the same as in DSHA, with a selected event of 7.8 magnitude and return period of 500 years. This because in the area where the methodology is applied, historical seismic events and instrumental data "are not enough to construct a Gutenberg-Richter relationship".

As final contribution to the scenario there is the neo-deterministic approach. Synthetic seismograms are generated by the modal summation technique. "Different source and structural models can be taken into account in order to create a wide range of possible scenarios from which to extract essential information for decision making" [10]. It is clear that correct modeling of earthquake sources are essential to all methods either probabilistic or deterministic. In the literature, a large number of earthquakes have been modeled in detail using seismological, geological and geodetic information. Several common traits have been found for earthquakes kinematics at periods longer than 3 sec. Radiation have been separated into two main components: a near field term responsible for the so called fling steps due to permanent, geodetic offsets; and the far field term that produces pulse like motions. Using seismological scaling relations it is possible to explain the main features of displacement spectra using classical seismological models at long periods. Unfortunately, seismic simulations may now be extended to the frequencies up to a few hertz, by means of dynamic rupture propagation, where rupture is simulated starting from the kinematic models and higher frequency modeling is still unrealistic.

\section{ENEA proposal for seismic input characterization}

The methodology used is based on the historical seismicity of the region, through a site approach, and a statistical analysis to obtain uniform hazard spectra for rigid soil sites. The methodology provide an analysis of PSHA for the selected site associated to an historical and statistical analysis of the regional seismicity having as result an uniform hazard response spectrum for the site. A historical analysis produces the evaluation of the maximum historical intensity, together with information on magnitude and epicentral distances of related events: these data are used in querying international strong-motion databases in order to select a set of real time-histories of the strong-motion related to the selected parameters and a severity index (SI) defined in term of minor differences between the target spectrum and the spectrum of the selected time-history. SI is a measure of the similarity between the response spectrum of the real time-history and response spectrum of the group to which the municipality belongs. Using the method of least squares, $\mathrm{SI}$ is assumed to be equal to the squared relative index (IQR) ( $y_{\mathrm{i}}=$ spectral ordinates of UHS; $\bar{y}_{i}=$ spectral ordinates of the selected records):

$$
S I=I Q R=\sqrt{\frac{\sum_{i=1}^{n}\left(y_{i}-\bar{y}_{i}\right)^{2}}{n}} / \frac{\sum_{i=1}^{n} \bar{y}_{i}}{n}
$$

The methodology was applied in several case studies. Among these the site of San Giovanni in Laterano in Rome and the site of the Museum of Reggio 
Calabria, Italy. The new data sets, recently made available to the scientific community by the INGV-DPC S1-Project, were considered in the studies, and in more details the Parametric Catalogue of Italian Earthquakes CPTI04 [11] and the related database of macroseismic intensity observations in Italy BDMI04 [12]. For the PSHA analysis, the INGV-DPC S1-Project diffused the Uniform Hazard Spectra (S1-UHS) calculated for a $5.5 \mathrm{~km}$ wide mesh covering the whole Italian territory and for several return periods, which are statistically analysed together with the local elastic spectra defined by the shape-parameters annexed in the Italian technical code.

\subsection{The site of San Giovanni in Laterano}

The analysis of San Giovanni in Laterano area was part of a research project for the structural preservation of the Egyptian Lateran Obelisk [13, 14]. The seismic input was characterized on the basis of the seismic zonation of the Latium region carried out by ENEA $[15,16]$. On the basis of the historical seismicity, the seismogenetic zonation of the national territory ZS9 [17] and the maximum acceleration at the site given by the present Italian national seismic classification, the entire region was first divided into six groups characterized by uniform hazard in terms of PGA. Then real acceleration time histories, compatible with the local seismological and geological characteristics, were selected from the world accelerometric databank and finally adapted to the average spectra, relative to the municipality of interest.

For the defined municipality, which includes the site of interest, the spectrum of the municipality group was selected and SI was identified. Then the events were divided by class of magnitude and the relative real accelerometric records were selected and scaled in order to approximate the response spectra relative to each return period. The selected time-histories were those obtained at Arienzo, Torre del Greco and Tricarico, during the November $23^{\text {rd }}, 1980$, CampanoLucano Earthquake, Italy $\left(\mathrm{M}_{\mathrm{S}}=6.9\right)$. Figure 1 shows the response spectra of the selected time-histories scaled for a return period of 2475 years and compared to the UHS of the municipality of interest.

The SI analysis gave the best result for the NS component of the accelerometric record obtained at Arienzo, which was used as seismic input for the scaled specimen of the Obelisk [18] together with those obtained by applying the same methodology LEMA_DES [19].

\subsection{The site of Reggio Calabria museum}

On the basis of the indices assigned to the end of the historical analysis of the local seismic hazard, it was possible to identify a number of groups of parameters that describe the characteristics of seismic events historically more burdensome for UAS (municipalities) of Reggio Calabria city in terms of epicentral intensity, magnitude and epicentral distance [20, 21]. Unfortunately, the intensity parameters, both the epicentral intensity and local intensity at the measuring stations of each event, are not always present in the databases currently available, so its use as a search key is likely to severely limit the 


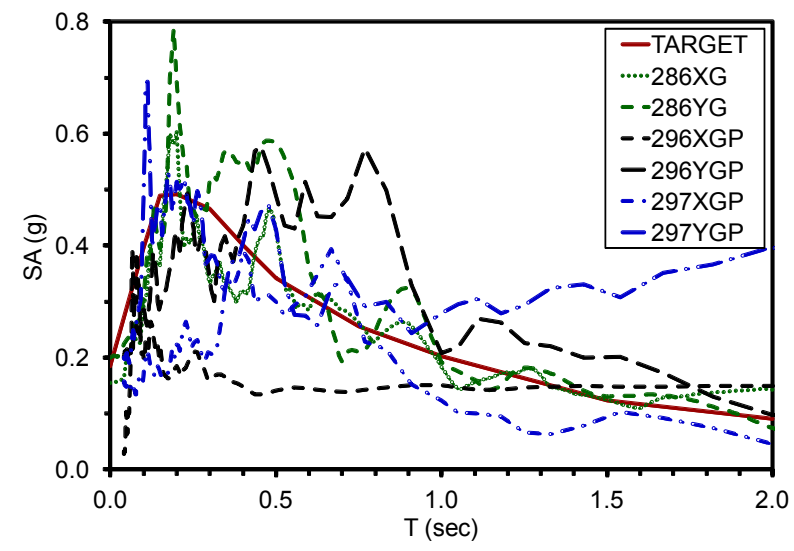

Figure 1: $\quad$ Response spectrum of Arienzo NS component (286XG) compared to other spectra and the target UHS ( $\mathrm{T}_{\mathrm{R}}=2475$ years).

number of selected recordings. For this reason, the query of accelerometric databases, was performed on the basis of the parameter magnitude and epicentral distance. Moreover, considering the goal of selecting accelerograms of reference for the study of seismic microzoning, the search was further restricted to the time-histories recorded by the accelerometric stations on free-field sites and placed on rigid soil. In a first step, after the historical analysis of selected events, the European strong-motion database [22] and that of the Consortium of Organizations for Strong-Motion Observation Systems (COSMOS) [23] were analysed to select records obtained in similar conditions of fault mechanism, soil and distance. Only recordings obtained in free-field were taken into account. It was not always possible to obtain records generated by a mechanism of rupture of normal fault, the dominant mechanism in the Mediterranean area, but less represented in the COSMOS database, while the European database has no records of events with magnitude higher than 7, with a normal focal mechanism. The historical analysis pointed out 2 main events, of February $5^{\text {th }}, 1783$ and of December $28^{\text {th }}, 1908$, respectively. The records selected to simulate them were:

1) the April $15^{\text {th }}, 1979$, earthquake $\left(M_{s}=7.4\right)$, recorded at UlcinijMontenegro station (epicentral distance $21 \mathrm{~km}, 9 \mathrm{~km}$ away from the fault), for the event of February $5^{\text {th }}, 1783$;

2) the October $18^{\text {th }}, 1989$, Loma Pietra earthquake $\left(M_{s}=7.1\right)$, recorded at Gilroy station (epicentral distance $28 \mathrm{~km}, 3 \mathrm{~km}$ away from the fault), for the event of December $28^{\text {th }}, 1908$. 


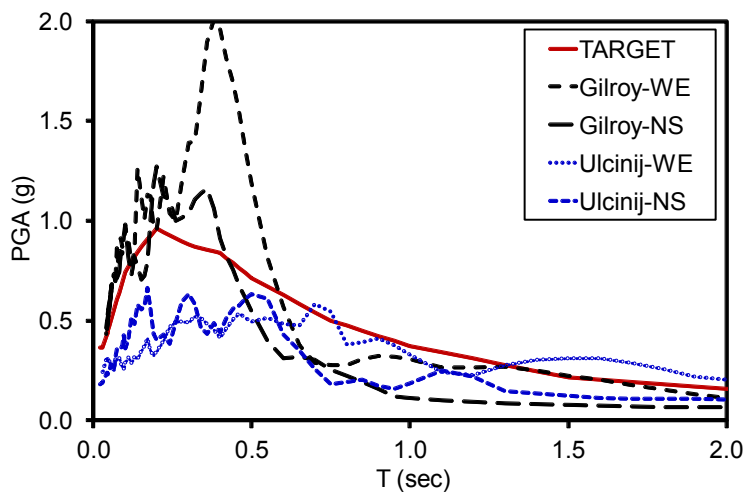

Figure 2: Comparison between the target UHS and the SA of the selected records for the Reggio Calabria site.

\section{Conclusions}

When dealing with seismic input characterization for a specific site, deterministic and probabilistic seismic hazard analyses should be complementary. The strength of one over the other depends on the earthquake mitigation decisions to be made, on the seismic environment, and on the scope of the project. The ENEA methodology for the seismic input characterization was designed set upon these bases. In fact, for the 2 sites considered in this paper, the UHS were obtained by means of the probabilistic approach while the seismic parameters to select the acceleration records were obtained with the deterministic one. This synergy of the two approaches is apparent.

The seismic hazard evaluation for the site of San Giovanni in Laterano in Rome followed the seismic zonation of the Latium region, in which UHS obtained by means of the PSHA were compared with SA of selected acceleration records, obtained from world wide databanks. Similarly the time-histories for Reggio Calabria Museum site were derived. For this site the target spectrum is the UHS at the site of the Museum of Reggio Calabria obtained from the INGVDPC-S1 project (grid of $5 \mathrm{~km}$ ). As stated the records were obtained for thrust mechanism.

This is of course a weak point of the methodology, which could be eliminated as the number of recorded events, included in the European and World wide databank, will increase. As a future development, it is possible to study the seismic simulation of the fault rupture to obtain the acceleration spectrum at the site, to compare with the selected time-history, even if in a limited frequency interval.

\section{References}

[1] Merrill R. G., Andraschko M., Stromgren C., Cirillo B., Earle K., Goodliff K., "A Comparison of Probabilistic and Deterministic Campaign Analysis 
for Human Space Exploration", Proc. AIAA Space 2008 Conference and Exposition (San Diego, CA, 9-11 Sept.), 2008.

[2] McGuire R. K., Seismic Hazard and Risk Analysis, EERI Monograph MNO-10, 2004.

[3] Cornell C. A., "Engineering seismic risk analysis", Bull. Seism. Soc. Am., 58(5), pp. 1583-1606, (Erratum: 59(4), p. 1733), 1968.

[4] Bommer J. J., Abrahmson N. A., "Why Do Modern Probabilistic SeismicHazard Analyses Often Lead to Increased Hazard Estimates?", Bull. Seism. Soc. Am., 96 (6), pp. 1967-1977, 2006.

[5] Abrahamson N., "Seismic Hazard Assessment: problems with current practice and future developments", First European Conference on Earthquake Engineering and Seismology (Geneva, 3-8 Sept.), Keynote Address K2, 2006.

[6] Madariaga R., "Earthquake dynamics and the prediction of Strong Ground Motion", First European Conference on Earthquake Engineering and Seismology (Geneva, 3-8 Sept.), Keynote Address K1b, 2006.

[7] Bommer J.J., "Deterministic vs. probabilistic seismic hazard assessment: an exaggerated and obstructive dichotomy", J. Earthquake Eng., 6 (special issue 1), pp. 43-73, 2002.

[8] Krinitzsky E. L., "How to obtain earthquake ground motions for engineering design, Eng. Geol.”, 65, pp. 1-16, 2002.

[9] Wang Z., "Seismic Hazard Assessment: Issues and Alternatives", Pure Appl. Geophysics, Springer Basel AG, 2010.

[10] Panza G.F., Vaccari F. and Cazzaro R., "Deterministic seismic hazard assessment", in F. Wenzel et al. (Eds), Vrancea Earthquakes: Tectonics, Hazard and Risk Mitigation, Kluwer Academic Publishers, The Netherlands, pp. 269-286, 1999.

[11] DBMI Working Group, Database macrosismico utilizzato nella compilazione di CPTI04. INGV, Milan, Italy. Available at http://emidius.mi.ingv.it/DBMI04/, 2007.

[12] CPTI Working Group, Catalogo Parametrico dei Terremoti Italiani, (CPTI04), INGV, Bologna, Italy. Available at http://emidius.mi.ingv.it/ CPTI04/, 2004.

[13] Buffarini G., Clemente P., Paciello A., Rinaldis D., "Vibration Analysis of the Lateran Obelisk". Proc., $14^{\text {th }}$ World Conference on Earthquake Engineering (Beijing, 12-17 October), Paper S11-055, IAEE \& CAEE, Mira Digital Publishing, Saint Louis, 2008.

[14] Buffarini G., Clemente P., Paciello A., Rinaldis D., "The Lateran Obelisk: Experimental analysis and modelling" Proc., International Conference on Protection of Historical Buildings, PROHITECH 09 (Rome, 21-24 June), 1, pp. 841-848, 2009.

[15] Rinaldis D., Martini G., Paciello A., Paolini S., Poggi F., Zini A., Analisi della sismicità regionale ai fini dell'individuazione di classi di comuni con situazioni omogenee di scuotibilità in occasione di eventi sismici, Final Report to Latium region, ENEA, 2008. 
[16] Orazi A., Colasanto F., Colombi A., Martini G., Paciello A., Pugliese A., Rinaldis D., Zini A., "The Seismic Zonation of Latium Region Based on New Criteria", Proc. 14th World Conference on Earthquake Engineering (Beijing, 12-17 October), IAEE \& CAEE, Mira Digital Publishing, Saint Louis, Paper07-0199, 2008.

[17] Meletti C., Galadini F., Valensise G., Stucchi M., Basili R., Barba S., Vannucci G., Boschi E., "A seismic source zone model for the seismic hazard assessment of the Italian territory", Tectonophysics, 450, pp. 85108, 2008.

[18] D’Imperio R., Rinaldis D., De Canio G., Mongelli M., Roselli I., Shake Table Tests on a Obelisk, in the Frame of the European Project PERPETUATE. RT/2013/6/ENEA ISSN/0393-3018, 2013.

[19] Lenti L., Martino S., "New procedure for deriving multifrequential dynamic equivalent signals (LEMA_DES): a test-study based on Italian accelerometric records". Bull Earthquake Eng., Springer, 2009.

[20] Rinaldis D., Restauro del Museo Nazionale di Reggio Calabria: Caratterizzazione dell'Input Sismico. ENEA Internal Report, 2012.

[21] Bozzano F., Lenti L., Martino S., Paciello A., Scarascia Mugnozza G., "Far-field seismic reactivation of large landslides due to self-excitation: new insights from the Cerda (Italy) case history", Int. J. of Earth Sciences, doi:10.1007/s00531-010-0514-5, 2010.

[22] Ambraseys N., Smit P., Berardi R., Rinaldis D., Cotton F. \& Berge-Thierry C., Dissemination of European Strong-Motion Data. CD-ROM collection. European Council, Environment and Climate Research Programme, 2000.

[23] COSMOS, Consortium of Organizations for Strong-Motion Observation Systems, http://www.cosmos-eq.org/. 